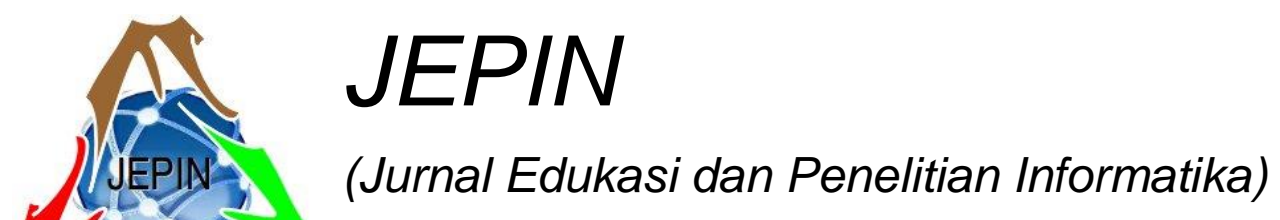

Vol. 6

No. 2

\title{
Perangkat Lunak Search Engine Citra Satelit LAPAN-A2 dan LAPAN-A3
}

\author{
Agus Herawan ${ }^{\# 1}$, Patria Rahman Hakim² ${ }^{* 2}$ Bambang Sigit Pamadi ${ }^{\# 3}$ \\ \#Pusat Teknologi Satelit - LAPAN \\ Jl. Cagak Satelit Km.04 Rancabungur - Bogor \\ 1agus.herawan@lapan.go.id \\ 2patria.rachman@lapan.go.id \\ 3bmbngsigiteyahoo.com
}

\begin{abstract}
Abstrak - Search engine yaitu kombinasi perangkat keras dan perangkat lunak komputer yang disediakan oleh perusahaan tertentu melalui website yang telah ditentukan. Seiring bertambahnya jumlah hasil citra yang dihasilkan satelit LAPAN-A2 dan LAPAN-A3 baik itu citra SpaceCam maupun citra LISA pada saat ini maka dibuat mesin pencari yang mampu mencari citra satelit dengan akurat. Hasil citra sampai saat ini hanya tersimpan pada folder-folder dengan penamaan khusus. Metode tersebut cenderung manual dan menyulitkan user untuk mencari citra dengan spesifikasi tertentu. Disamping itu, kebutuhan pengguna terhadap data citra pada waktu tertentu menjadi permasalahan utama. Stasiun bumi satelit LAPAN setiap hari secara rutin melakukan kegiatan akuisisi dan pengolahan data citra satelit LAPAN. Data citra satelit LAPAN hasil pengolahan di stasiun bumi ini kemudian diintegrasikan ke dalam satu sistem search engine. Oleh karena itu, fasilitas ini dirancang dan diimplementasikan untuk memenuhi kebutuhan pengguna. Makalah ini akan memaparkan rancang bangun sistem search engine citra satelit LAPAN yang berbasis web. Sistem serach engine yang akan dikembangkan ini diharapkan dapat memudahkan pengguna di Indonesia maupun dunia untuk mengakses dan mengunduh data citra satelit yang telah dihasilkan oleh satelit LAPAN-A2 dan LAPAN-A3 secara langsung. Disamping sebagai media penyimpanan, dengan menggunakan sistem search engine citra berbasis web akan mempermudah Pusteksat untuk mendiseminasikan produk satelit LAPAN-A2 dan LAPAN-A3
\end{abstract}

Kata kunci-LAPAN-A2, LAPAN-A3, search engine, satelit, SpaceCam, LISA

\section{Pendahuluan}

Satelit Lapan A2/LAPAN-Orari diluncurkan dengan Roket PSLV C-30 dan Bandar Antariksa Satish Dhawan, Sriharikotta, India, pada tanggal 28 September 2015 [1].
Sesuai dengan misi tersebut, satelit ini dibekali dengan 2 buah kamera yaitu kamera video dan kamera digital resolusi tinggi (Space Cam). Kamera video satelit LAPAN A2 memiliki sensor dengan ukuran 752 x 582 pixel dengan resolusi $6 \mathrm{~m}$ dan swath $5 \mathrm{~km}$ pada ketinggian 630 $\mathrm{km}$. Sedangkan kamera digital memiliki sensor dengan ukuran 2048 x 2048 pixel dengan resolusi 4 m dan swath $7 \mathrm{~km}$ pada ketinggian yang sama. Satelit LAPAN-A3 diluncurkan dengan Roket PSLV C-34 dari Bandar Antariksa Satish Dhawan, Sriharikotta, India, tanggal 22 Juni 2016. LAPAN-A3/LAPAN-IPB memiliki berat 115 kg dengan ketinggian (altitude) $508 \mathrm{~km} \mathrm{[2].} \mathrm{Sama} \mathrm{halnya}$ dengan satelit LAPAN-A2, satelit LAPAN-A3 memiliki muatan optik didalamnya, yaitu LISA (Line Imager Space Application), Space Cam, Kamera Video, dan Microbolometer. Satelit LAPAN-A2 dan LAPAN-A3 telah banyak menghasilkan citra baik citra Space Cam LAPAN-A2 dan LAPAN-A3 maupun citra LISA LAPAN-A3 [3]. Satelit LAPAN-A2 telah banyak menghasilkan citra dari kameda digital SpaceCam untuk wilayah Indonesia saja yang berhasil diakuisisi oleh beberapa stasiun bumi yang tersebar di Indonesia. Satelit LAPAN-A3 juga telah banyak menghasilkan citra yakni citra hasil dari kamera digital SpaceCam untuk wilayah luar negeri serta citra yang dihasilkan sensor LISA (Line Imager Scanning Application). Search engine (mesin pencarian) yaitu kombinasi perangkat keras dan perangkat lunak komputer yang disediakan oleh perusahaan tertentu melalui website yang telah ditentukan. Banyak peneliti dan survey menunjukkan bahwa Google adalah search engine nomor satu diikuti oleh Yahoo [4]

Beberapa penelitian terkait search egnine yaitu Penelitian [5] menerapkan metode LSI (Latent Semantic Index) untuk mencari/menemukan informasi berdasarkan makna keseluruhan (conceptual topic atau meaning) dari suatu dokumen bukan hanya makna kata per kata pada ebook. Penelitian [6] telah menerapkan mesin pencari dan teknik-tekniknya seperti pengindeksan dan pencarian di world wide web dilakukan dalam makalah ini. metode 
untuk membuat pencarian mesin dengan menggunakan JSoup dan Apache Lucene.

Penelitian [7] telah mengartikulasikan desain aplikasi Web yang mengintegrasikan manajemen data geospasial, visualisasi dengan kemampuan pencarian semantik dan teknologi web-mining. Sistem ini mampu memproses berbagai pertanyaan dan pencarian yang dilakukan oleh pengguna dan merespons dalam waktu paling singkat dengan data yang paling komprehensif dan deskriptif. Basis data katalog data citra satelit LAPAN juga telah dikembangkan. Sistem basis data katalog ini diharapkan dapat memudahkan pengguna di seluruh Indonesia untuk mengakses dan mengunduh data citra satelit LAPAN secara langsung [8]. Penelitian [9] telah mengembangkan aplikasi search engine dengan metode depth first search. Pembangunan aplikasi ini tujuan utamanya adalah sebagai alat yang memudahkan pengaksesan informasi dalam sebuah portal atau situs tertentu, kemudian tujuan lainnya adalah juga untuk memberi kecepatan dalam pengaksesan terhadap informasi tersebut. Namun aplikasi dibatasi hanya untuk melakukan pencarian file atau informasi ke dalam lingkungan internet.

Penelitian [10] melakukan survei lengkap dari berbagai alat dan teknik yang digunakan untuk SEO. Search engine yang digunakan untuk menemukan informasi apa pun di internet. Penelitian [11] mengembangkan sistem pencari pengaruh wilayah geografis (Yordania) dan budaya lokal, dan mengidentifikasi pengaruh dan hubungan kata kunci masyarakat lokal dalam meningkatkan peringkat situs web Penelitian [12] melakukan pencarian dalam dokumen teks dengan konsep-konsepnya. Pencarian teks yang relevan dokumen dengan bantuan kata kunci atau permintaan dikenal sebagai pencarian informasi. Teknik pengambilan informasi yang digunakan untuk meningkatkan pengindeksan dokumen yang disimpan dan kinerja permintaan mesin pencari dikenal sebagai LSA (Latent Semantic Analisis).

Penelitian [13] melakukan investigasi teknik search engine. Teknik SEO On-page dan Off-page Google dipelajari dan dielaborasi. Analisis kami menargetkan situs www.studying-in-germany.org, dengan melakukan dan menerapkan faktor SEO optimasi On-page dan Offpage. Teknik penggunaan optimasi mesin pencarian atau Search Engine Optimization (SEO) yang akan digunakan untuk meningkatkan trafik pengunjung pada sebuah halaman website dan juga digunakan agar sebuah halaman website dapat terdeteksi atau tertelusuri dengan baik pada sebuah mesin pencari [14]. Penelitian [15] melakukan pencarian bahasa berbasis kata kunci dan pencarian berbasis semantik. IBRI-CASONTO didasarkan pada berbagai teknologi seperti data resource deskripsi framework (RDF) dan grafik ontologis. Percobaan mewakili dalam dua bagian, pertama itu menunjukkan perbandingan antara Entity-Search dan Klasik-Search di dalam IBRI-CASONTO itu sendiri, kedua itu membandingkan Entity-Search of IBRI-CASONTO dengan mesin pencari yang saat ini digunakan seperti google.

Permasalahan yang terjadi yakni dengan banyaknya citra yang berhasl diakuisisi dari kedua satelit tersebut setiap harinya, maka ketika melakukan pencarian citra satelit yang diperlukan akan menjadi sulit, karena masih tersimpan dalam bentuk folder. Seiring dengan pertambahan jumlah citra tersebut maka diperlukan sebuah metode untuk mencari citra satelit agar bila membutuhkan referensi maka citra satelit yang diperlukan dapat dengan mudah dapat ditemukan. Salah satu solusi untuk memepercepat pencarian citra satelit makan metode search engine adalah solusinya. Berdasarkan permasalahan di atas maka solusi untuk pencarian data citra satelit tersebut akan dirancang sebuah prototype sistem search engine citra satelit LAPAN berbasis web. Disamping sebagai media penyimpanan, search engine citra satelit berbasis web akan mempermudah Pusteksat untuk mendiseminasikan produk satelit LAPAN. Dengan menerapkan search engine diharapkan pencarian data citra satelit akan semakin akurat dan optimal.

\section{Metodologi Penelitian}

Metode Penelitian yang akan digunakan disajikan pada Gambar 1.

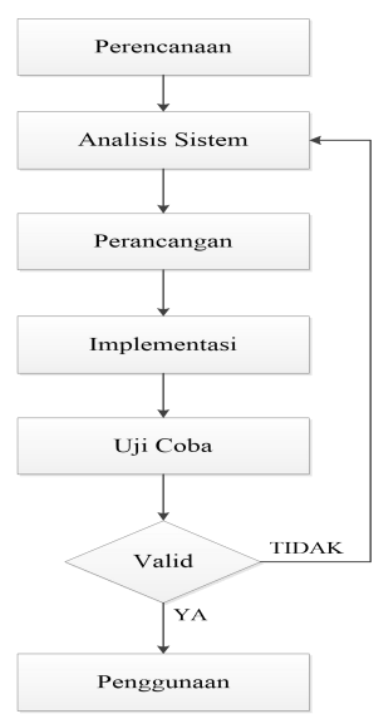

Gambar 1. Metode penelitian

\section{A. Perencanaan Sistem}

Tahap perencanaan merupakan suatu tahap pembelajaran mengenai kasus atau permasalahan yang akan diselesaikan. Kegiatan yang dilakukan pada tahap ini yaitu seperti mengambil data dengan melakukan observasi erta melakukan studi literatur untuk menguasai dan memahami dasar dasar teori yang mendukung penelitian.

\section{B. Analisis Sistem}

Tahap analisis sistem dilakukan terhadap kebutuhan aplikasi yang akan dibangun. Dalam aplikasi ini 
dikhususkan pada fungsi search engine atau mesin pencari agar pencarian pada citra satelit LAPAN dapat akurat dan optimal. Pemilihan algoritma pencarian string yang ingin diterapkan dan dikembangkan pada sistem search engine ini .

\section{Perancangan Sistem}

Tahap perancangan sistem dilakukan melalui 3(tiga) tahap, yaitu:

1) Perancangan Basis Data: Perancangan sistem secara basis data (database) dapat dilakukan menggunakan pendekatan terstruktur meliputi: ERD (Entity Relationship Diagram), Relasi Entitas dan spesifikasi file.

2) Perancangan Sistem Secara Umum: Perancangan Sistem secara keseluruhan dalam penelitian ini dilakukan dengan menggunakan Diagram Konteks, Data Flow Diagram (DFD), flowchart sistem, struktur navigasi dan tampilan sistem berikutnya yang merupakan simbolsimbol yang digunakan untuk menggambarkan urutan proses yang terjadi didalam suatu program komputer secara sistematis dan logis.

3) Rancangan Sistem Secara Detail: Merancang form-form yang diperlukan dalam melakukan suatu sistem yang akan dikembangkan.

\section{Impelementasi Sistem}

Tahap implementasi pada penelitian ini merupakan tahap pembuatan sistem, sistem yang akan dibangun dengan menggunakan bahasa pemprograman PHP dan HTML, untuk database menggunakan MySQL (XAMPP) sebagai web server (localhost) serta text editor menggunakan Visual Studio Code.

\section{E. Testing}

Tahap uji coba ini dilakukan untuk mengukur kemampuan sistem dalam melakukan pencarian dokumen yang relevan dengan kata kunci yang dimasukkan oleh pengguna. Pada pengujian ini mengikuti prinsip relevansi pada information retrieval yaitu menggunakan ukuran recall,precision. Ukuran recall dan precision itu bergantung pada apa yang sesungguhnya dimaksud dengan dokumen yang relevan itu dan memastikan relevan-tidaknya sebuah dokumen.

\section{HASIL DAN PEMBAHASAN}

\section{A. Perencanaan}

Data citra satelit yang dapat digunakan yaitu data yang sudah diolah sebelumnya oleh para pusteksat yang berada di LAPAN. Data yang diberikan berbentuk citra dengan ukuran lebar dan panjang berbeda satu sama lain dengan format png. Data citra tersebut berupa citra yang menampilkan gunung, pulau serta wilayah di Indonesia dan Luar Negeri. Citra yang diakuisisi oleh LAPAN dihasilkan dari satelit LAPAN-A2 dan LAPAN-A3 dengan masing-masing produk satelit. Terdapat 2 produk satelit yang digunakan yaitu Spacecam dan LISA. Sistem yang akan dikembangkan pada penelitian ini yaitu untuk mengoptimalkan pencarian pada metadata citra satelit bukan hanya berdasarkan judulnya melainkan juga deskripsi pada citra tersebut, sehingga sistem pencarian ini mampu mencari keterkaitan antara kata kunci yang dimasukkan pada pencarian dengan deskripsi mengenai citra satelit tersebut

\section{B. Analisis Sistem}

Analisis sistem yang akan dikembangkan yaitu pada proses pencarian string dengan kaidah proses retrieval yaitu preprocessing teks, pemberian bobot pada setiap kata kemiripan atau similarity antara kata yang dimasukkan pada kata kunci dengan data yang sudah diolah di dalam database. Langkah awal admin menambahkan data dokumen citra satelit ke dalam database untuk kemudian dilakukan pengolahan teks. Langkah berikutnya admin mengontrol untuk preprocessing pada dokumen sehingga menjadi beberapa kumpulan term.

Setelah dilakukan preprocessing, setiap term dibentuk menjadi sebuah matriks term agar dapat dilakukan proses indexing yaitu dengan menghitung jumlah term yang sama lalu memberikan bobot term pada dokumen menggunakan TF-IDF. Proses yang dilakukan pada tahap ini juga dilakukan pada setiap term yang dimasukkan dalam query. Langkah selanjutnya untuk meningkatkan relevansi hasil pencarian pada dokumen maka perlu ditingkatkan hubungan semantic antar term.

Adapun flowchart tahapan dari sistem yang akan dikembangkan ini disajikan pada Gambar 2.

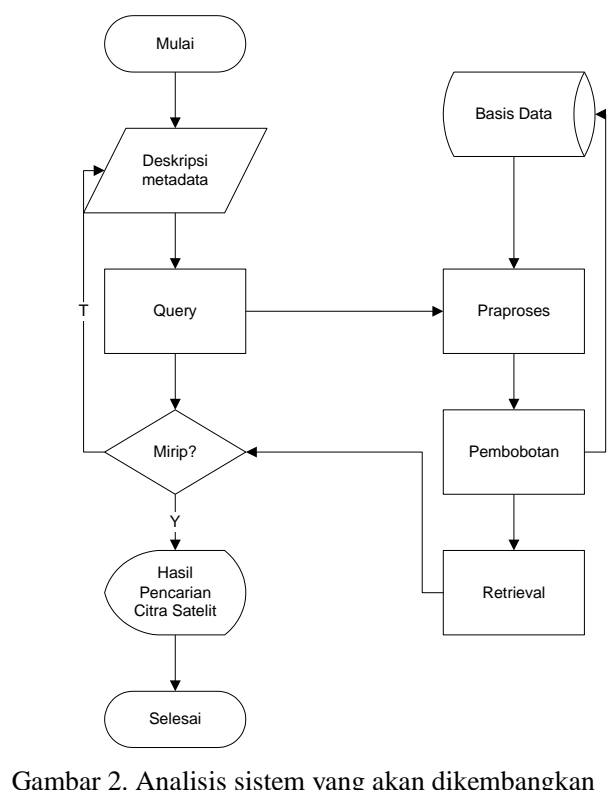

\section{Perancangan}

Diagram Konteks pada sistem ini melibatkan pada dua entitas yaitu: user dan admin. Pertama admin memasukkan data citra satelit ke dalam database sistem. 
Kemudian user melakukan pencarian dengan memasukkan query berupa kata kunci pencarian ke dalam sistem. Jika kata kunci yang dimasukkan sesuai dengan data dalam dokumen citra maka data hasil pencarian dapat dilihat oleh user. Berikut diagram konteks pada sistem ini dapat dilihat pada Gambar 3.

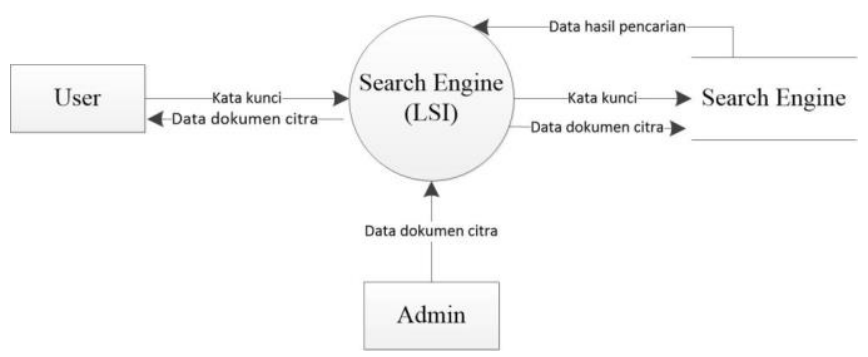

Gambar 3. Diagram konteks search engine

ERD merupakan suatu model jaringan yang menggunakan susunan data yang disimpan oleh sistem secara abstrak. Tujuan utama adalah menunjukan obyek data dan relationship pada obyek tersebut. Adapun ERD pada sistem ini disajikan pada Gambar 4.

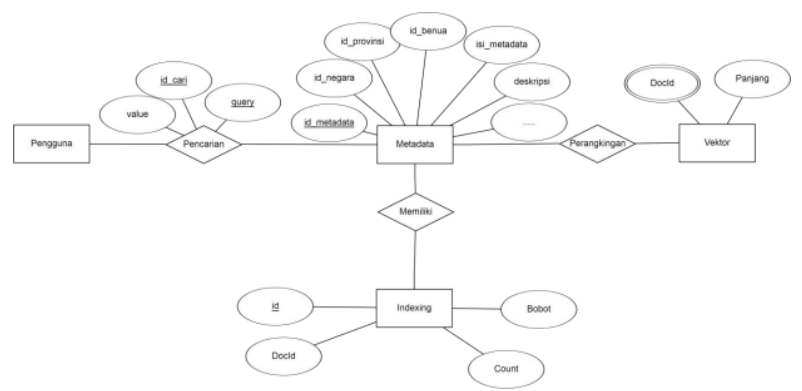

Gambar 4. Entity relationship diagram

Langkah selanjutnya yakni merancang tampilan menu sistem pencarian. Halaman ini merupakan halaman awal ketika membuka sistem pencarian citra satelit. Pada rancangan halaman awal sistem ini terdapat form pencarian dengan tab-menu berisi menu awal pencarian berdasarkan lokasi, menu kedua berisi pencarian berdasarkan tanggal-pengambilan satelit, menu ketiga berisi pencarian berdasarkan produk satelit, dan keempat pencarian berdasarkan titik koordinat latitude dan longitude serta maps untuk menunjukkan lokasi citra yang akan ditampilkan. Perancangan halaman utama disajikan pada Gambar 5.

\section{Implementasi}

Sistem ini dibuat dengan menggunakan text editor Visual Studio Code dan dijalankan pada server local Xampp. Bahasa pemrograman yang digunakan yaitu PHP 7.1 dan Mysql yang telah disediakan pada web server.

Tahap pembuatan database menggunakan Mysql Server yang digunakan untuk menyimpan data citra satelit. Tabel yang terdapat pada database tersebut diantaranya yaitu tabel negara, tabel benua, tabel provinsi, tabel metadata, tabel index, tabel pencarian, tabel vektor, tabel kata dasar dan tabel user. Implementasi database pada sistem ini disajikan pada Gambar 6.

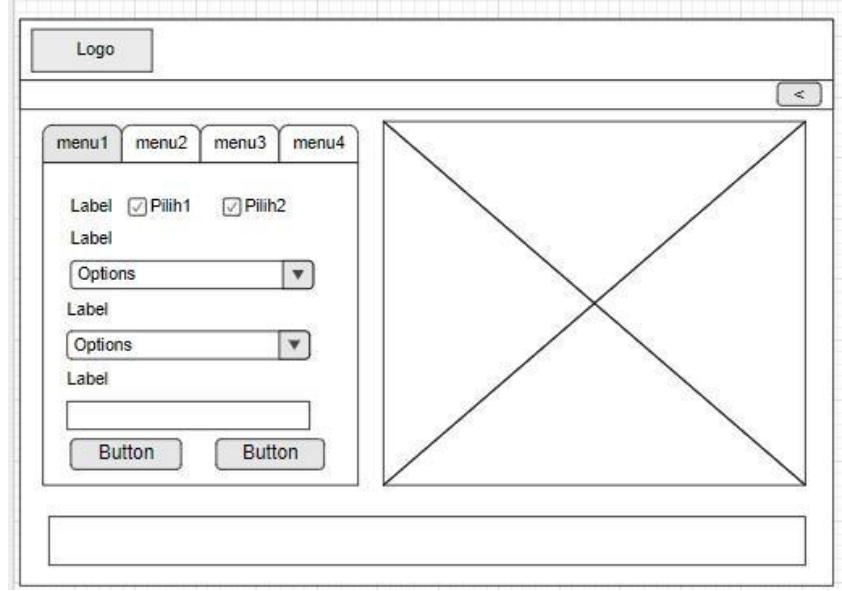

Gambar 5. Rancangan halaman utama search engine

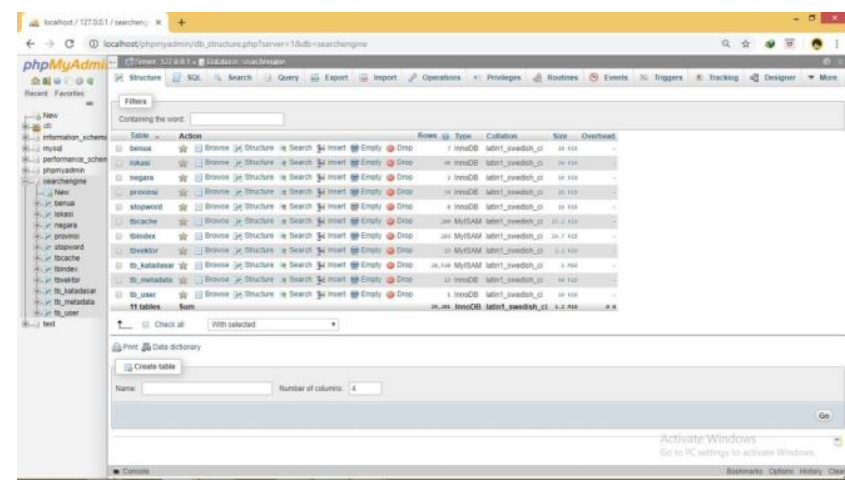

Gambar 6. Implementasi basis data

\section{E. Halaman Utama}

Halaman utama merupakan halaman awal ketika user membuka sistem pencarian citra satelit. Pada halaman ini terdapat fasilitas pencarian melalui form yang tersedia pada tab menu. User dapat mencari metadata citra satelit dengan memasukkan query kata kunci pada menu pencarian berdasarkan lokasi. Tampilan halaman utama dapat dilihat pada Gambar 7.

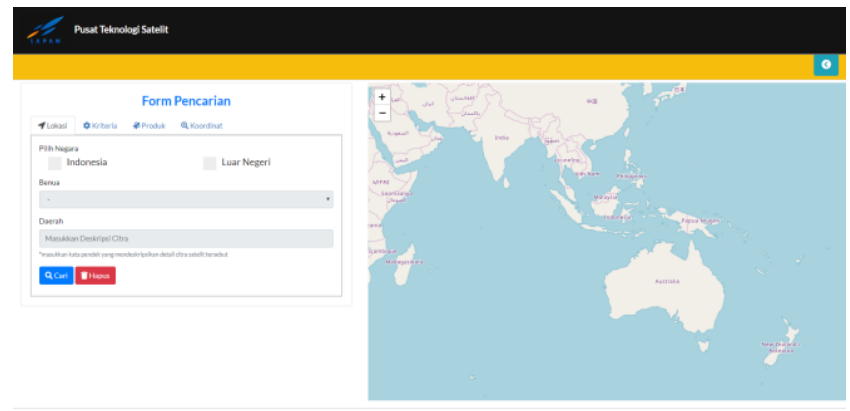

Gambar 7. Halaman utama search engine citra satelit LAPAN

Pencarian citra satelit berdasarkan lokasi dilakukan dengan memasukkan pilihan kriteria seperti negara, benua dan provinsi. Kemudian user memasukkan deskripsi atau 
nama daerah dari citra yang diinginkan. Tombol cari digunakan untuk menginputkan permintaan user terhadap query yang sudah dimasukkan dimana nantinya akan diteruskan pada hasil pencarian citra satelit. Tampilan pencarian berdasarkan lokasi dapat dilihat pada Gambar 8 .

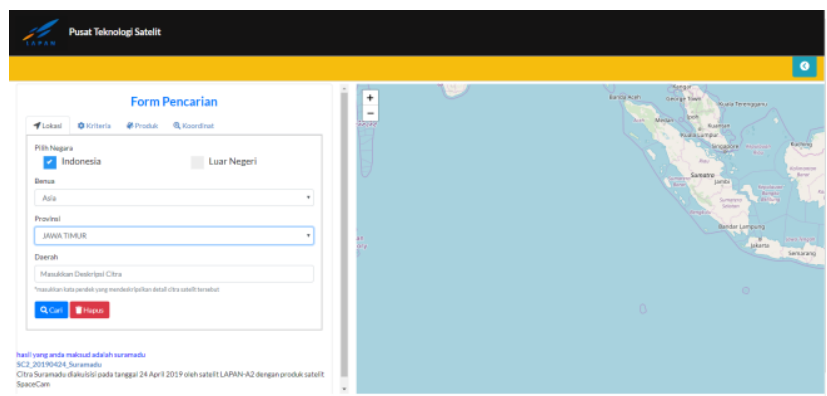

Gambar 8. Pencarian citra satelit pada search engine citra satelit LAPAN

Halaman hasil pencarian citra satelit ini merupakan halaman yang menampilkan data citra satelit yang memiliki nilai kemiripan atau sesuai dengan kata kunci yang dimasukkan oleh user. Halaman ini berisi judul metadata citra satelit dan deskripsi detail dari citra satelit yang telah dimasukkan kedalam database. Tampilan hasil pencarian citra satelit dapat disajikant pada Gambar 9.

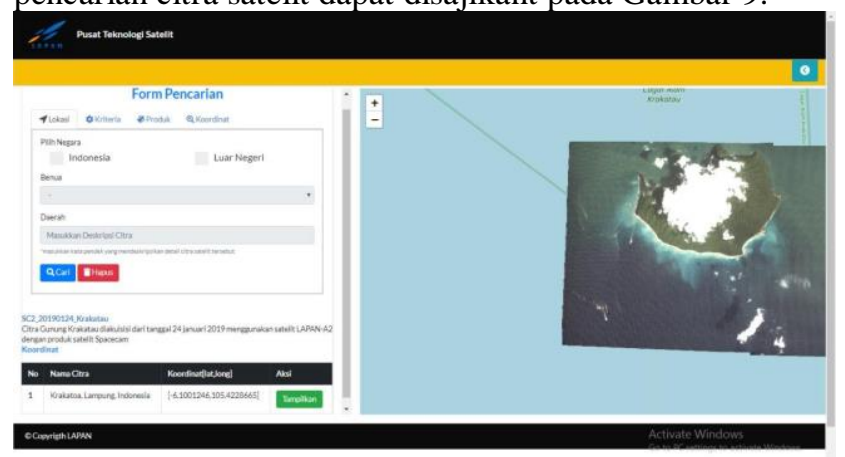

Gambar 9. Hasil pencarian citra satelit

\section{F. Pembahasan}

Sistem search engine citra Satelit LAPAN ini bertujuan untuk memudahkan pusteksat dalam menemukan citra satelit yang diinginkan sesuai query kata kunci yang dimasukkan kedalam sistem. Pada tahap awal data citra satelit ditambahkan oleh admin pusteksat kedalam database untuk nantinya dapat diolah menggunakan text preprocessing. Adapun data citra satelit yang berhasil ditambahkan dapat dilihat pada tabel metadata citra satelit dapat dilihat pada Gambar 10.

Selain itu admin juga dapat menekan tombol hitung pada menu hitung bobot untuk melakukan proses pembobotan dari hasil indexing menggunaan TF-IDF. Adapun perhitungan bobot yang dihasilkan pada setiap kata (term) dalam dokumen dapat dilihat pada Gambar 11.

Pada halaman utama menu pencarian user memasukkan deskripsi pada form input kemudian query tersebut dilakukan preprocessing sama seperti pada halaman admin setelah itu dilakukan pembobotan dengan TF-IDF kemudian dihitung nilai kemiripan antara query tersebut dengan deskripsi pada data dalam dokumen citra satelit.
Hasil pencarian dari query tersebut berupa nilai kemiripan yang diambil dari dokumen citra satelit dengan kata kunci yang dimasukkan dari nilai tertinggi hingga terendah. Jika kata kunci yang dimasukkan tidak sesuai namun memiliki satu unsur kata yang sama maka sistem akan tetap dapat menampilkan data citra satelit yang memiliki keterhubungan dengan kata tersebut. Namun selainnya jika tidak terdapat kata yang sesuai maka data citra satelit tidak dapat ditemukan. Adapun pengujian dilakukan dengan memasukkan query "Gunung aktif yang pernah meletus ?" maka hasilnya disajikan pada Gambar 12
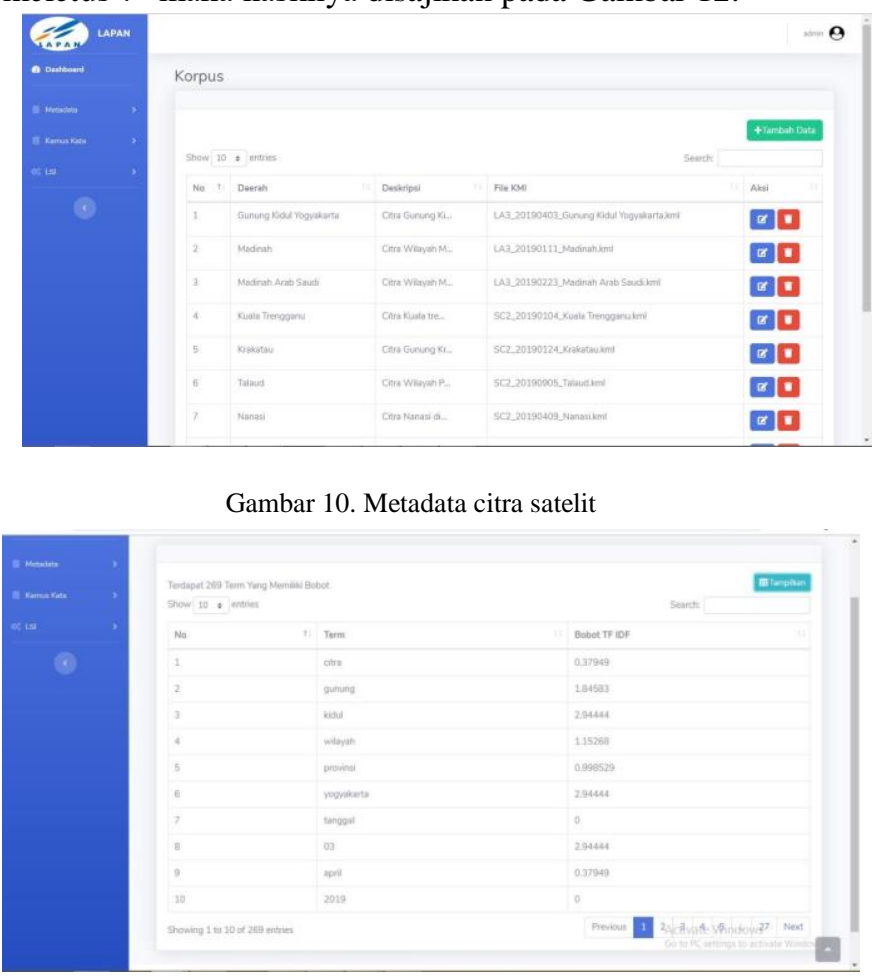

Gambar 11. Pembobotan dengan TF-IDF

Hasil yang anda maksud adalah citra gunung krakatau Ditemukan pada $1.0013580322266 \mathrm{E}-5$ detik

SC2_20190124_Krakatau

Citra Gunung Krakatau diakuisisi dari tanggal 24 januari 2019 menggunakan satelit LAPAN-A2 dengan produk satelit Spacecam

Gambar 12. Pengujian pencarian data citra

\section{G. Ujicoba}

Uji coba struktural ini dilakukan untuk memastikan apakah keadaan program ini terstruktur dengan baik sesuai yang diharapkan. Hal ini bertujuan agar didapatkan hasil yang diinginkan. Jika terjadi kesalahan atau hasil yang didapat tidak sesuai dengan yang diinginkan maka proses akan kembali. Hasil dari uji coba struktural disajikan pada Tabel 1. 
TABEL I

UJICOBA STRUKTURAL

\begin{tabular}{|l|l|c|}
\hline No & Form & Keterangan \\
\hline 1. & Halaman Utama & Sesuai \\
\hline 2. & Pencarian Berdasarkan Lokasi & Sesuai \\
\hline 3. & $\begin{array}{l}\text { Pencarian Berdasarkan } \\
\text { Tanggal Pengambilan }\end{array}$ & Sesuai \\
\hline 4. & Pencarian Berdasarkan Produk & Sesuai \\
\hline 5. & Pencarian Berdasarkan Koordinat & Sesuai \\
\hline 6. & Hasil Pencarian Citra Satelit & Sesuai \\
\hline 7. & Halaman Login & Sesuai \\
\hline 8 & Halaman Dashboard Admin & Sesuai \\
\hline 9. & Halaman Metadata Citra Satelit & Sesuai \\
\hline
\end{tabular}

Setelah dilakukan ujicoba struktural, langkah berikutnya dilakukan uji coba fungsional dilakukan dengan cara mengklik setiap link dan melihat halaman yang akan terbuka. Hasil uji coba fungsional disajikan pada Tabel 2.

TABEL II

UJICOBA FUNGSIONAL

\begin{tabular}{|c|c|l|c|}
\hline No & Fungsi & \multicolumn{1}{|c|}{$\begin{array}{c}\text { Hasil yang } \\
\text { diharapkan }\end{array}$} & Ket \\
\hline 1. & Pencarian & $\begin{array}{l}\text { Sistem } \\
\text { menampilkan data } \\
\text { citra satelit } \\
\text { berdasarkan query } \\
\text { yang dimasukkan } \\
\text { pada kata kunci }\end{array}$ & Berfungsi \\
\hline 2. & $\begin{array}{c}\text { Tombol } \\
\text { Login }\end{array}$ & $\begin{array}{l}\text { Masuk ke dalam } \\
\text { dashboard admin }\end{array}$ & Berfungsi \\
\hline 3. & Tombol & $\begin{array}{l}\text { Admin berhasil } \\
\text { menambahkan data }\end{array}$ & Berfungsi \\
\hline 4. & Tombol Edit & $\begin{array}{l}\text { Admin berhasil } \\
\text { mengubah data }\end{array}$ & Berfungsi \\
\hline 5. & $\begin{array}{c}\text { Tombol } \\
\text { Hapus }\end{array}$ & $\begin{array}{l}\text { Admin berhasil } \\
\text { menghapus data }\end{array}$ & Berfungsi \\
\hline
\end{tabular}

\section{KESIMPULAN}

Berdasarkan hasil penelitian yang telah dilakukan dapat ambil kesimpulan sebagai berikut:

1. Pengembangan sistem search engine citra satelit LAPAN-A2 dan LAPAN-A3 telah berhasil diimplementasikan.

2. Pencarian citra satelit LAPAN yang dilakukan dengan menerapkan indexing dan pembobotan dengan TF-IDF pada pencarian berdasarkan deskripsi lokasi pada citra tersebut. Sistem pencarian ini mempermudah pusteksat dalam menemukan dokumen citra satelit yang ingin ditemukan dengan cepat dan optimal

3. Proses indexing yang dilakukan meringankan beban database dan mempercepat proses pencarian kata

\section{REFERENSI}

[1] S. Harsono, "Tracking Satelit LAPAN-A2 Menggunakan Program Open Source", Prosiding SIPTEKGAN, pp 307-316, 2016

[2] A.Syafrudin, W.Hasbi, A.Rahman, "Camera Payload Systems For The LAPAN A2 Experimental Microsatellite". In Proceeding of 34th Asian Conference on Remote Sensing, ACRS 2013.

[3] A. Saifudin, M. Mukhayadi, "LAPAN-A2 Attitude Control Strategy for Equatorial Surveillance Mission", In Proc. of the 9th IAA Symposium on Small Satellites for Earth Observation, 2013.

[4] L., A., Abdillah, K Falkner, D. Hemer, ".Information Retrieval And Storing For The Contents Of Scientific Journals (HDR poster day /poster presentation). Adelaide, South Australia: The University of Adelaide, 2010

[5] G. Susanto, H., L., Purwanto, " Information Retrieval Menggunakan Latent Semantic Indexing Pada Ebook", Jurnal Smatika, vol.8, no.2, pp. 74-79, 2018

[6] M. Balipa, R. Balasubramani, " Search Engine using Apache Lucene", International Journal of Computer Applications, Vol 127 - No.9, pp.27-30, 2015

[7] M. Kumar, " Satellite Image Repository System and Web Enabled Search Engine", In Proceedings of international Conference on Advances in Electronics, Electrical and computer Science Engineering, pp.65-69, 2012

[8] A. Herawan, S. Salaswati, " Perancangan Basis Data Katalog Citra Satelit LAPAN", Jurnal Informatika, vol. 5 , no.2, pp. 301307, 2018.

[9] N. Juliasari, J. Sitompul, "Aplikasi Search Engine dengan Metode Depth First Search (DFS)", BIT, vol 9 no.1, pp. 9-12, 2012

[10] P. Ankalkoti, " Survey on Search Engine Optimization Tools \& Techniques" , Imperial Journal of Interdisciplinary Research (IJIR), vol. 3, no. 5, pp. 40-43, 2017

[11] F. Zaghoul, O. Rababah, A. Fakhouri," Website Search Engine Optimization: Geographical and Cultural Point of View", In Proceedings of UKSim-AMSS 16th International Conference on Computer Modelling and Simulation, 2014

[12] K. Rajandeep, K. Manpreet, " Latent Semantic Analysis Searching Technique for Text Documents", International Journal of Engineering Development and Research, vol .3 , no. 2, pp. 803806, 2015

[13] S. Krrabaj, F. Baxhaku, D. Sadrijad, " Investigating Search Engine Optimization Techniques For Effective Ranking: A Case Study Of An Educational Site", In Proceeding of 6th Mediterranean Conference on Embedded Computing (MECO), Montenegro, 2017

[14] Himawan, Arisantoso, A. Saefullah, " Analisa Pengaruh Penggunaan Search Engine Optimization (Seo) Pada Website ECommerce", Prosiding Seminar Nasional Sistem Informasi Indonesia (SESINDO), 2015

[15] A. Sayed, A. Muqrishi, "IBRI-CASONTO: Ontology-Based Semantic Search Engine", Egyptian Informatics Journal, vol 18, no. 3,pp.181-192, 2017 